\title{
Research on the Cultivation of Students' Innovative Ability in the Basic Teaching of Visual Communication Design*
}

\author{
Bailin Xiao \\ Northeast Electric Power University \\ Jilin, China
}

\begin{abstract}
As an important part in the three core fields of art design, specialty of visual communication design contains the content of traditional graphic design subject. This field has been expanding along with technological and scientific progress, development of new media technology, and development and application of new energy and new materials, and has intersected with other fields, gradually forming a new field of design that is closely related and collaborative with other visual media. The cultivation of creative thinking and innovative ability has always been an essential content of the visual communication design specialty in colleges and universities.
\end{abstract}

Keywords-visual communication design; research on innovative ability; basic teaching of design

\section{INTRODUCTION}

As an important part in the three core fields of art design, specialty of visual communication design contains the content of traditional graphic design subject. This field has been expanding along with technological and scientific progress, development of new media technology, and development and application of new energy and new materials, and has intersected with other fields, gradually forming a new field of design that is closely related and collaborative with other visual media. The cultivation of creative thinking and innovative ability has always been an essential content of the visual communication design specialty in colleges and universities.

At present, courses of visual communication design specialty in colleges and universities in China are generally divided into two parts: basic courses of design and specialized courses of design. There is a progressive sequential relation between basic courses and specialized courses under the professional system of visual communication design. As the starting point for visual communication design majors to enter the field of design, basic courses of design are a connection point transforming from elementary painting education to elementary design education. It is also an important process for students to establish systematic visual communication design

*Project Source: This paper is a general planning topic of "the 13th FiveYear Plan" of Education Science in Jilin Province: Research on the "Dual Creative" Talent Training Model of Visual Communication Design in Colleges and Universities GH170359 Research Results. concepts. The study of basic courses of design is not only to learn design skills and accumulate design experience, but also gradually develop students' design innovative ability in the learning process.

\section{LIMITATIONS OF CURRENT BASIC COURSE TEACHING OF VISUAL COMMUNICATION DESIGN}

Design basis is a basic platform for visual communication design. Its courses almost include the basic subject knowledge that must be mastered in this major (basic courses of design in this paper not only refer to the modeling foundation and constitution foundation in traditional concepts), such as font, format, graphics, printing, design history and so on. There is not only relative independence but also some internal relations among different courses. Basic courses of visual communication design mainly cover design expression basis, design technology foundation and design theory foundation. Meanwhile, due to continuous development of the times and science and technology and constant change of design concepts, education of visual communication design in China is also always changing and adjusting.

\section{A. Limitations on the Understanding of the Essence of Courses}

Longitudinally, the current teaching of visual communication design courses focus on the cultivation of students' innovative ability in the teaching process of specialized courses rather than in the teaching process of basic courses of design. The basic teaching of visual communication design attaches importance to the modeling performance ability, and stresses that the skilled application ability of visual presentation technology and techniques should accord with the teaching goal of basic courses of design. However, paying too much attention to the mastery of technology but ignoring the cultivation of creative thinking and innovative ability will make students form a thinking set. Many professional teachers think that basic courses of design are to enable students to learn relevant design theories and master basic design skills, while the innovative ability should be the task of the specialized course stage. This limited comprehension actually confuses the relationship between foundation and innovation, and results in the situation that basic courses of design are only designed to grasp the form of performance technology. 
Students' creative thinking is limited, and their innovative ability is even out of the question.

Visual communication design is a practical and applied subject. The research on the teaching of basic design courses places more emphasis on the cultivation of students' practical ability, and there is a common mistake of emphasizing practice rather than theory. In the process of teaching, there is a neglected phenomenon for basic courses of design theory such as history of design, design aesthetics, design culture research, design principles, design methodology and so on. In the process of teaching, teachers repeat what the book says and students mechanically memorize the knowledge according to notes. As a result, the study of design theory is reduced to a low level of knowledge-based learning, which cannot play a theoretical support role for professional practice learning, resulting in a disconnection between theory and practice. Basic course teaching of visual communication design cannot be simply divided into theoretical type and practical type, and theory and practice are an interactive unity. Practice is the essential characteristic of design. But without the guidance of theory to practice, design can only be a castle in the air. Valuing the study of basic theory of design is related to the integrity of students' follow-up specialized knowledge learning and cultivation of innovative ability.

\section{B. Single and Stylized Course Contents}

Single contents and stylized teaching process of basic courses of visual communication design are substantive problems in teaching. The name of visual communication design specialty was determined in 2012, and before that it was called graphic design. The courses of visual communication design specialty in domestic colleges and universities today basically follow the previous course system of graphic design. Basic courses of design offered generally include professional modeling (sketching and colors), constitution design, decoration foundation, graphic design, character design, layout design, packing modeling design, computer-aided design, design theory and other traditional courses. Although the name of individual courses has been revised, many subjects are often the continuation of years of teaching program in the process of teaching implementation, which neither conforms to the development of the major nor arouses students' interest in learning and inquiry. During teaching, students put a lot of effort into the completion of skills training homework, and have little time to think deeply about or innovate their task design. Design practice often contains some imitations. For example, in the plane composition course, teachers will first concentrate on the theoretical teaching of the concept and principle of composition as required by the syllabus, and then arrange the design training topics. Students will do design exercises based on examples, and then teachers will give guidance and comment. In the courses, students only design for the sense of form, and seldom consider design creativity and the thinking analysis process. The lack of understanding of basic courses of design directly leads to the long-term continuation of the traditional content and the neglect of the importance of theoretical basis and humanistic knowledge in the process of ability training guided by technology.

\section{Immobilized Course Offering Model}

Aiming at training innovative talents of design, there is a lack of long-term rational planning for basic courses of visual communication design in colleges and universities in China. Generally speaking, basic courses of visual communication design follow a fixed pattern that theory is prior to practice, and modeling is prior to constitution, and painting is prior to graphing, and realism is prior to transforming, and concrete is prior to abstract, and plane is prior to stereo, and technology is prior to creativity. However, such a sequence is not established in accordance with the internal logic rules of the course, and more based on accumulation of habits and experience on the basis of learning from Bauhaus' design education system. This kind of fixed course setting often ignores the systematicness of academic course studying. The courses are isolated from each other, and there is a lack of continuity and application of knowledge. In the process of learning, it is difficult for students to understand the teaching objectives that should be achieved in the design of basic courses. It has great blindness and is not conducive to the cultivation of students' innovative ability.

\section{Disconnection from Subsequent Specialized Courses}

The teaching of basic courses of visual communication design is disjointed from the following specialized courses, which is mainly manifested in the fact that basic courses and specialized courses of design are independent closed systems and lack of internal connection. The teaching of design basis mainly provides support for theoretical cognition, performance skills, thinking analysis, and ability training for the follow-up development of specialized courses. However, most students do not actively integrate the basic knowledge of design into professional design after learning specialized courses. This phenomenon indicates that the basic course system of design is isolated and stays in a narrow condition in the entire education system. Besides, it also proves that teaching and training of simple skills and experience in the basic design courses cannot provide a strong support platform for academic course studying.

\section{THE IMPORTANCE OF DEVELOPING INNOVATIVE ABILITIES IN BASIC COURSES OF DESIGN}

Basic courses of design are an important carrier for the cultivation of innovative ability. In the education practice of design, we should fully realize that the creative thinking and innovative ability of art is cultivated in the process of constantly accumulating and strengthening knowledge and skills, intellectual ability and personality quality. Therefore, in the teaching of basic courses, we should cultivate students' consciousness of innovation from the stage of knowledge and skills accumulation, and make them feel and understand what innovation is and cultivate their sensitivity to innovation. The instrumental role of basic courses of design is irreplaceable. Meanwhile, it also shoulders the responsibility of cultivating students' logical thinking ability, scientific cognition ability, design management ability, humanistic quality and communication ability, which are important components of the structure of innovative ability. 
Basic courses of design are the best stage to cultivate innovative ability. The cultivation of innovative ability should not have a phase, but run through the whole design education link including the basic course of design. Innovation itself cannot depend on a part or stage of a design. The stage of basic courses of design is the best stage to cultivate creative thinking and innovative ability, while the stage of specialized courses is to synthetically use and deepen this ability. The teaching of basic design courses must complete the cultivation of innovative consciousness and ability to achieve a win-win situation of technology and ability.

\section{MEASURES FOR THE CULTIVATION OF INNOVATIVE ABILITY IN BASIC COURSES OF VISUAL COMMUNICATION DESIGN}

\section{A. Strengthening the Teaching Concept of Cultivating Innovative Ability}

Innovative ability is not a single skill or technology but a complex and three-dimensional ability structure. Its essence is the ability to tackle problems creatively. In this ability structure, it includes both core innovative thinking and many comprehensive factors such as cognition, emotion, will, and skills. Knowledge is neither wisdom nor competence. When talking about education, Laue, a famous physicist, said that the important thing was not to acquire knowledge, but to develop thinking ability. Only by transforming knowledge into ability can it be truly useful. The teaching of basic courses of design based on the cultivation of innovative ability is to not only cultivate students' ability to acquire rich knowledge and master performance skills, but also cultivate students' good innovative thinking ability and the ability to transform this thinking into solving problem.

\section{B. Scientificcally Constructing a Basic Course System of Design}

The construction of a scientific and reasonable course system for visual communication design can guarantee the teaching quality of visual communication design specialty, and help students learn professional knowledge and cultivate innovative ability. In the education stage of basic courses of design, reasonable setting of training courses of technology, skills and innovative thinking can effectively break students' thinking set, guarantee the instrumentality of basic courses, and improve students' innovative thinking ability. The cultivation of students' innovative ability is a systematic work. It is far from enough to perfect the course setting only, and we should also run through the innovation concept in the basic teaching of design to enhance students' innovation consciousness. Different courses have different perspectives on the cultivation of students. Therefore, we should coordinate the relationship between various courses, stimulate students' innovative thinking from different angles, and cultivate their innovative ability. The teaching methods should also be diversified, and multiple teaching methods should be adopted to bring more design inspiration to students, so as to improve their design innovative ability.

Visual communication design not only has distinct comprehensiveness and complexity, but also a unique interdisciplinary. It not only involves culture, society, history, economy and other fields, but also intersects with social sciences, humanities, art, natural sciences and other disciplines. Therefore, to enhance the comprehensive quality of students and improve their innovative ability, visual communication design education must pay attention to the cross-cooperation with other disciplines, break a single curriculum system, expand students' professional knowledge, and enable students to find design inspiration from other subject knowledge, so as to form a personalized creative concept.

\section{Optimizing the Contents of Basic Courses of Design}

To cultivate innovative design talents, we must fully recognize the universality and exploitability of innovation. The universality of innovation means that the ability to innovate is an innate ability of human beings. It evolves with the evolution of human brain, and its existence form is manifested as innovation potential. The exploitability of innovation means that human's innovative ability can be stimulated, educated and upgraded, and then the innovation potential can be transformed into apparent ability, which is what we usually called as innovative ability. How to stimulate and improve students' innovative ability in the stage of basic courses of design? Firstly, it is necessary to make the content of the course close to professional practice, fully embody the openness and diversity of the teaching content, and enable students to establish a thinking mode combining rational and perceptual thinking. Secondly, we must break the dilemma of independent teaching of each course in terms of teaching ideas, reintegrate the scattered and hidden knowledge structure, achieve the combination of richness and systematization, logicality and interestingness, divergence and analyticity, and highlight the exploratory consciousness of topic design. Finally, on the basis of optimizing the knowledge structure, we must enhance the cultivation of students' visual ability, thinking ability and practical ability, explore the ways to cultivate students' innovative ability in teaching, and optimize the content of basic courses from enhancing the consciousness of innovation, so that students' creative potential in the basic stage of design education can be fully unlocked.

\section{Reforming the Way of Assessment and Evaluation}

The traditional assessment methods of basic courses of design are basically divided into two categories, one is the theoretical closed-book examination mode, and the other is the teacher comprehensive evaluation and grading mode. Both assessment methods emphasize the results of learning and ignore the students' ability of knowledge transformation and innovation in the learning process. This result is often contingent, but students' learning process is real. Therefore, these two kinds of assessment methods are defective to some extent, which cannot fully reflect students' creative thinking and innovative ability. Diversified assessment methods should be based on the different characteristics of each course. The formulation of diversified and operable assessment methods should start from innovative thinking and technical performance, so that the assessment method can be changed from the traditional "inspection-based assessment" to "learning-based assessment". For example, self-assessment, group assessment and teacher evaluation are used in course 
assessment and evaluation to achieve the goal of "promoting learning, improvement innovation by evaluation". We also can adopt the method of "replacing test by showing", enhance students' attention to the learning process and encourage students to seek difference, innovation and change, cultivate their innovative ability, and create a good learning atmosphere.

\section{CONCLUSION}

The cultivation of students' creative ability in visual communication design is a systematic education project. In the whole education process, the basic courses of visual communication design are the best stage to cultivate students' innovative ability. Through the research on the teaching of basic courses of visual communication design, we hope to comprehensively improve the teaching quality of basic courses of visual communication design and effectively achieve the teaching goal of cultivating students' innovative ability.

\section{REFERENCES}

[1] Zhou Yanfang. Research on Talent Cultivation of Art Design Subjects in Applied Engineering Colleges [J]. Education Exploration, 2017 (2): 84-85. (in Chinese)

[2] Huang Tao. Talent Cultivation of Art Design Major in Engineering Colleges from the Teaching Theory of Bauhaus [D]. Hebei University, 2007 Fan Yingliang. Representational \& Abstract: New Reflection of Basic Design Thinking Process [J]. Art \& Design, 2014 (11): 122-124. (in Chinese) 